\title{
Rapid, Presumptive Identification of Seed-Based Toxins using Direct Analysis in Real Time Mass Spectrometry (DART-MS) and its Variants
}

\author{
Edward Sisco ${ }^{a^{*}}$, Natalie Damaso ${ }^{b}$, Elizabeth L. Robinson ${ }^{a}$, James M. Robertson ${ }^{c}$, and Thomas P. Forbes ${ }^{a}$ \\ ${ }^{a}$ National Institute of Standards and Technology, 100 Bureau Drive, Gaithersburg, MD 20899 \\ ${ }^{b}$ Visiting Scientist Program, Research Support Unit, Federal Bureau of Investigation Laboratory Division, 2501 Investigation Pky, \\ Quantico, VA, 22135, USA \\ ${ }^{\mathrm{C}}$ Research Support Unit, Federal Bureau of Investigation Laboratory Division, 2501 Investigation Pky, Quantico, VA, 22135, USA \\ *edward.sisco@nist.gov, 301-975-2093
}

\begin{abstract}
Detection of seed-based toxins is a need for forensic chemists when suspected poisonings occur. The evidence that is found is often physically unidentifiable, as the seeds are mashed to extract the toxins. This work investigates potential strategies for rapid detection of seed-based toxins using chemical signatures obtained by direct analysis in real time mass spectrometry (DART-MS). Seven toxins (digoxin, digitoxin, hypaconitine, hyoscyamine, lanatoside, oleandrin, and scopolamine) and six seeds containing these toxins were studied. While detection of four of the toxins was readily attainable, detection of digoxin, digitoxin, and lanatoside was hindered by the inability to thermally desorb these larger compounds under normal operating conditions. The use of DART-MS variants capable of higher temperature analysis (thermal desorption (TD)-DART-MS and infrared thermal desorption ((IRTD)-DART-MS) enabled detection of these compounds. The low-level toxin concentrations and limited number of seeds available for analysis led to detection difficulties from both seed mashes and methanolic seed mash extracts. Principal component analysis (PCA) of generated mass spectra enabled differentiation of seed species, even in the cases when the toxins were undetectable.
\end{abstract}

\section{Keywords}

Toxins; DART-MS; Mass Spectrometry; Detection; TD-DART-MS; IRTD-DART-MS

\section{Introduction}

Suspected poisonings are one of many types of cases that forensic chemists and toxicologists may be required to analyze. These cases can be gaseous-based (e.g., carbon monoxide), chemical-based (e.g., illicit drugs, pharmaceuticals, or industrial chemicals), or biological-based (e.g., toxic components of plants or animals). There are numerous plants that contain toxic chemicals in one or more of their parts (e.g,. leaves, bark, seeds, etc.)[1]. Seeds are a common toxin-containing tissue and are often mashed to release the toxin and introduced into foods, or otherwise administered through ingestion and inhalation.

A major challenge with seed mashes is the inability to obtain rapid, presumptive information since, in most instances, the physical attributes are lost and cannot be used to preliminarily identify the potential toxin. Evidence is often found at a suspects home having already been mashed and identification, therefore, must be made via extraction and chemical analysis by a technique such as gas chromatography mass 
spectrometry (GC-MS)[2,3] and liquid chromatography mass spectrometry (LC-MS)[4,5] or toxicology analysis from a suspected victim[6,7]. Having a technique that is capable of rapidly identifying either the toxin present or the species of seed(s) contained in the mash not only provides investigators with more timely information but also aids toxicologists or chemists in deciding which extraction protocol (e.g., organic, acidic, or alkaline) to use for the isolation of the toxin from the mash.

In recent years ambient ionization mass spectrometry (AI-MS) techniques have been the focus of increased forensic application, research, and implementation. Benefits of these techniques, which include techniques such as direct analysis in real time mass spectrometry (DART-MS)[8,9] and atmospheric solid analysis probe mass spectrometry (ASAP-MS)[10], include the rapid ( $<1 \mathrm{~min})$ analysis of samples with minimal to no sample preparation at sensitivities similar to those offered by chromatographic techniques. DART-MS has been demonstrated for a wide range of forensic applications[9] such as the analysis of drugs[11], explosives[12], paints[13], and sexual assault lubricants[14]. DART-MS has also been applied to the analysis of plant-based materials[15-17]. A significant body of work exists on the detection of novel psychoactive substances (NPSs) present in plant materials (e.g., kratom)[18,19]. Other work has focused on using DART-MS to understand enzymatic pathways in plants based on the analysis of their leaves[20]. Combining DART-MS with thin layer chromatography (TLC) has also been demonstrated to provide a way to separate compounds from plant extracts[21]. A number of different configurations, or variants, of traditional DART-MS have also been developed to address challenges such as reproducibility, precision, and the need for higher desorption temperatures[9].

This work provides a foundation for the use of DART-MS to detect toxins and analyze seed mash and seed mash extracts, specifically when the analysis of the intact seed is not possible. A total of seven different toxins from six different seed species were targeted. Development of optimized methods for analysis required the ability to detect a large range of molecular weights and volatilities which proved difficult for traditional DART-MS. However, utilization of two DART-MS variants (TD-DART-MS and IRTD-DART-MS) allowed for detection of all examined toxins. Once representative responses of the toxins were established, analysis of the seed mashes and extracts of the seed mashes were completed to evaluate the ability to detect the toxins in the presence of the complex seed matrices. The multivariate technique, principal component analysis (PCA) was also employed to differentiate the chemical signatures of seed species.

The use of these techniques for the detection of seed mashes for the presumptive identification of toxins has not been demonstrated before. However, given the successful results of this work, and the increasing prevalence of AI-MS techniques, especially DART-MS, in forensic laboratories, this approach offers a unique opportunity to deliver rapid presumptive information to chemists, toxicologists, and investigators.

\section{Materials and Methods}

\section{Chemicals and Seeds}


A total of seven commonly encountered plant-based toxins were investigated in this work: digitoxin, digoxin, hypaconitine, hyoscyamine, lanatoside, oleandrin, and scopolamine. The compounds were purchased either as pure solids or, for scopolamine, as a $1 \mathrm{mg} \mathrm{mL}^{-1}$ solution in methanol from Sigma-Aldrich (St. Louis, MO, USA). Relevant information for these compounds can be found in Table 1. All compounds were dissolved in LC-MS grade methanol (Fisher Scientific) to create $1 \mathrm{mg} \mathrm{mL}^{-1}$ solutions which were serially diluted to lower concentrations, as necessary.

Table 1. Relevant information for the toxins investigated in this study.

\begin{tabular}{|c|c|c|c|}
\hline Compound & Formula & $\begin{array}{c}\text { Monoisotopic } \\
\text { Mass (Da) }\end{array}$ & $\begin{array}{c}\text { Seed(s) Analyzed Containing } \\
\text { Compound }\end{array}$ \\
\hline Digoxin & $\mathrm{C}_{41} \mathrm{H}_{64} \mathrm{O}_{14}$ & 780.4296 & D. purpurea \\
\hline Digitoxin & $\mathrm{C}_{41} \mathrm{H}_{64} \mathrm{O}_{13}$ & 764.4347 & D. purpurea \\
\hline Hypaconitine & $\mathrm{C}_{33} \mathrm{H}_{45} \mathrm{NO}_{10}$ & 615.3044 & A. napellus \\
\hline Hyoscyamine & $\mathrm{C}_{17} \mathrm{H}_{23} \mathrm{NO}_{3}$ & 289.1678 & D. inoxia, D. stramonium \\
\hline Lanatoside & $\mathrm{C}_{49} \mathrm{H}_{76} \mathrm{O}_{20}$ & 984.4930 & D. purpurea \\
\hline Oleandrin & $\mathrm{C}_{32} \mathrm{H}_{48} \mathrm{O}_{9}$ & 576.3298 & N. oleander, T. peruviana \\
\hline Scopolamine & $\mathrm{C}_{17} \mathrm{H}_{21} \mathrm{NO}_{4}$ & 303.1471 & D. inoxia, D. stramonium \\
\hline
\end{tabular}

To understand how well detection of toxins occurs in real-world matrices, six seed species from the FBl's Scientific Response and Analysis Unit (SRAU) were also analyzed and included: Aconitum napellus (Strictly Medicinal LLC), Datura inoxia, Datura stramonium (Strictly Medicinal LLC), Nerium oleander, Thevetia peruviana, and Digitalis purpurea. Two of these seeds studied were from the same genus $(D$. inoxia and $D$. stramonium) and two were from different genera that contained the toxin oleandrin ( $N$. oleander and $T$. peruviana). For all studies, the seeds were analyzed as seed mash. Seed mashes were created by crushing two seeds from each species using a mortar and pestle. The seed mash was sampled both directly and as a methanol extract of the mash, created by adding approximately $500 \mu \mathrm{L}$ of methanol to the dry seed mash and then vortexing at 3,000 rpm for approximately $30 \mathrm{~s}$.

\section{$D A R T-M S$}

Three different variations of the DART-MS platform were evaluated in this work and included traditional DART-MS, thermal desorption (TD-DART-MS), and infrared thermal desorption (IRTD-DART-MS). All variations were mounted on a JEOL JMS T100-LP (Peabody, MA, USA) time-of-flight mass spectrometer and employed the use of a DART-SVP ionization source (lonSense, Saugus, MA, USA). In all cases, identical mass spectrometer settings were utilized. For positive ionization mode, the following parameters were used: an orifice 1 voltage of $+20 \mathrm{~V}$, a ring lens voltage of $+5 \mathrm{~V}$, an orifice 2 voltage of $+5 \mathrm{~V}$, a peaks voltage of $1000 \mathrm{~V}$, an orifice temperature of $120^{\circ} \mathrm{C}$, and a mass range of $\mathrm{m} / z 100$ to $\mathrm{m} / \mathrm{z} 1100$ at 2 scans $\mathrm{s}^{-1}$. For negative ionization mode, the following parameters were used: an orifice 1 voltage of $-20 \mathrm{~V}$, a ring 
lens voltage of $-5 \mathrm{~V}$, an orifice 2 voltage of $-5 \mathrm{~V}$, a peaks voltage of $1000 \mathrm{~V}$, an orifice temperature of 150 ${ }^{\circ} \mathrm{C}$, and a mass scan range of $\mathrm{m} / \mathrm{z} 200$ to $\mathrm{m} / \mathrm{z} 1100$ at 2 scans s$^{-1}$. Extracted spectra were averaged across a $2 \mathrm{~s}$ peak and background subtracted. The $\mathrm{m} / \mathrm{z}$ tolerance of the mass spectrometer was $\pm 5 \mathrm{mDa}( \pm 0.005$ $\mathrm{Da})$.

For traditional DART-MS a gas stream temperature of $450^{\circ} \mathrm{C}$ and a $50 \mathrm{~V}$ exit grid voltage were used. Ultrapure helium was used as the DART ionization gas. Glass microcapillary rods (Corning, Corning, NY, USA) were used for sampling. For analysis of seed mash, the rod was rubbed in the seed mash for several seconds and then directly introduced into the DART gas stream. For solution analysis, $1 \mu \mathrm{L}$ of solution was pipetted onto the closed end of the glass rod and then introduced directly into the DART gas stream.

For TD-DART-MS, a custom-built thermal desorber, described elsewhere in greater detail[22,23] was placed in line between the DART source and the mass spectrometer inlet. This configuration utilized the $\operatorname{Vapur}^{\circledR}$ aerodynamic-assist interface to mount to the MS and a confining glass $\mathrm{T}$-junction to connect the TD unit, DART source, and Vapur interface. A thermal desorber temperature of $300^{\circ} \mathrm{C}$, a Vapur flow rate of $4.0 \mathrm{~L} \mathrm{~min}^{-1}$, a DART gas stream temperature of $400^{\circ} \mathrm{C}$, and a DART exit grid voltage of $50 \mathrm{~V}$ were used. Ultra-pure nitrogen was used as the DART ionization gas. Samples were introduced into the TD unit using polytetrafluoroethylene (PTFE) coated fiberglass wipes (DSA Detection, North Andover, MA, USA). TDDART-MS is different from traditional DART-MS in that the sample can be reproducibly introduced in the TD unit which allows for a more repeatable and, often, more sensitive analysis.

Since the maximum temperature for the TD-DART-MS configuration was $300^{\circ} \mathrm{C}$, IRTD-DART-MS, which can reach desorption temperature in excess of $500^{\circ} \mathrm{C}$, was also investigated. The IRTD-DART configuration used a custom-built IRTD unit, described in detailed elsewhere[24], which was mounted to the Vapur interface, like the TD-DART-MS. Desorption was achieved using a $10 \mathrm{~s}$ IR lamp pulse at $100 \%$ power, generating a maximum temperature of $400^{\circ} \mathrm{C}$. The DART and Vapur parameters were identical to those used in the TD-DART-MS configuration. PTFE-coated wipes were also used for sample introduction. For both TD-DART-MS and IRTD-DART-MS, solid seed mash samples were analyzed by rubbing the PTFE-coated wipes in the seed mash for several seconds, brushing off any large pieces of seed material, and then introducing the wipe directly into the thermal desorber. Solutions were analyzed by pipetting $1 \mu \mathrm{L}$ of the liquid directly onto the PTFE-coated wipe, allowing it to dry, then introducing the wipe into the thermal desorber.

\section{Statistical Analysis}

PCA was conducted on triplicate mass spectra from each seed and sample preparation methods (i.e., dry seed mash and seed extract). Each mass spectrum included 64,587 data points. In order to compare chemical signatures of seeds, especially when identifiable toxins were not observed, PCA reduced the large number of variables or mass spectral peaks to fewer principal components[25,26]. As described in the literature, a custom Matlab (Mathworks Inc., Natick, MA, USA) code was employed to import the above 
referenced background subtracted spectra and perform PCA[27]. Given the widely variable response to various toxins and seed matrices, each spectrum was normalized to the base peak prior to analysis. PCA loading and scoring values were determined and presented for the first three principal components.

\section{Results and Discussion}

\section{Spectral Responses and Sensitivities of Standards}

The first component of this study sought to establish which toxins could be detected using traditional DARTMS. Analysis showed that detection of four of the seven toxins (hypaconitine, hyoscyamine, oleandrin, and scopolamine) was readily achievable using baseline settings. All four compounds formed protonated molecules, $[\mathrm{M}+\mathrm{H}]^{+}$as displayed in Figure 1 and Figures S1, S2, S3, and S4.8 Both hypaconitine and oleandrin also readily produced $\left[\mathrm{M}_{-} \mathrm{C}_{2} \mathrm{H}_{3} \mathrm{O}_{2}\right]^{+}$ions which had intensities equal to or greater than the protonated molecule. In addition to identifying the spectral responses of these compounds, the approximate detection limits, defined as the lowest mass level analyzed that produced a response with a signal-to-noise ratio of at least 3:1 for three replicates, were also identified and are shown in Table 2. Under baseline conditions, no detectable signature for digitoxin, digoxin, or lanatoside was obtained.

To identify if any of these compounds were more likely to produce negative ions, analysis in negative ion mode by DART-MS was also completed. Oleandrin was the only compound found to elicit a response in negative ionization mode (Figure $1 \mathrm{C}$ and S5), forming a deprotonated molecule, [M-H]', at nominal $\mathrm{m} / z 575$. Detection of oleandrin in negative mode was found to be slightly more sensitive than in positive mode, potentially due to the formation of multiple ions in positive ionization mode, lowering the absolute abundance of any one peak. Additional experiments were completed at an increased DART gas stream temperature of $550^{\circ} \mathrm{C}$ to see if detection of digoxin, digitoxin and/or lanatoside was possible. However, no detectable signature was obtained in either ionization mode.
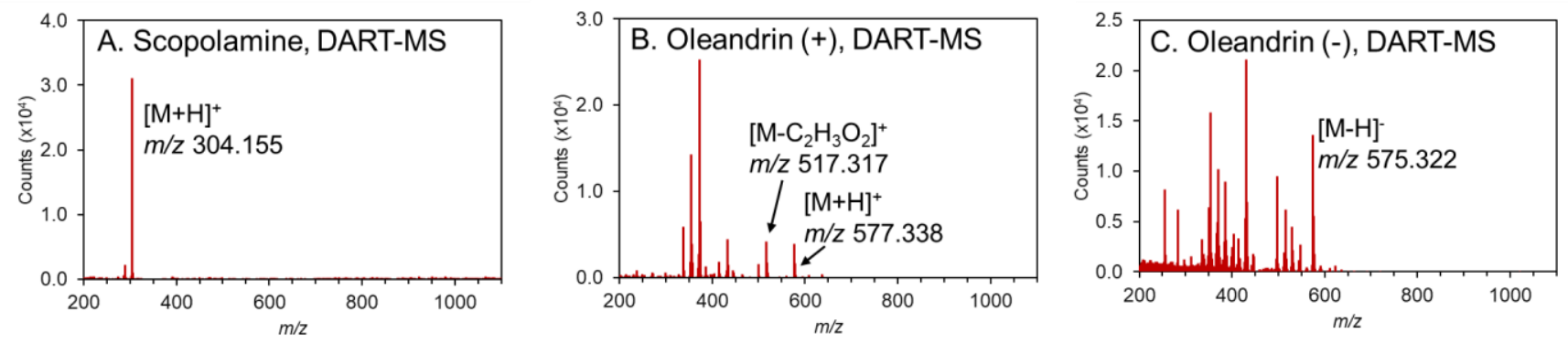

Figure 1. Representative mass spectra of scopolamine when analyzed by (A.) DART-MS, as well as oleandrin analyzed by DART-MS in (B.) positive ionization mode and (C.) negative ionization mode.

The inability to see digoxin, digitoxin, and lanatoside by traditional DART-MS led to the investigation of DART variants capable of higher desorption temperatures. TD-DART-MS was first investigated as it has been shown to thermally desorb larger molecules, such as rodenticides[28]. The maximum desorption 
temperature of $300{ }^{\circ} \mathrm{C}$ was used. While this temperature was lower than that of the DART temperature used in this work, the enclosed configuration ensures minimal temperature loss compared to DART-MS where rapid loss of temperature in the gas stream has been observed[29,30].

Utilizing TD-DART-MS, detection of all seven toxins was achieved. As with traditional DART-MS, detection of hypaconitine, hyoscyamine, oleandrin, and scopolamine was readily achieved in positive ionization mode. Similar ionization pathways were found for these compounds, as shown in Figure 2 (A., C., and E.) and Figures S1, S2, S3, and S4. Oleandrin produced a small ammonium adduct in positive ionization mode (Figure 2(C.)) as well as a dominant nitrate adduct peak in negative ionization mode (Figure 2(E.)) - both of which may be attributed to the use of nitrogen instead of helium as the DART ionization gas. Approximate limits of detection for TD-DART-MS (Table 2) were lower or equal to those for traditional DART-MS. This agrees with previous research that showed enhanced sensitivity using this configuration[22].
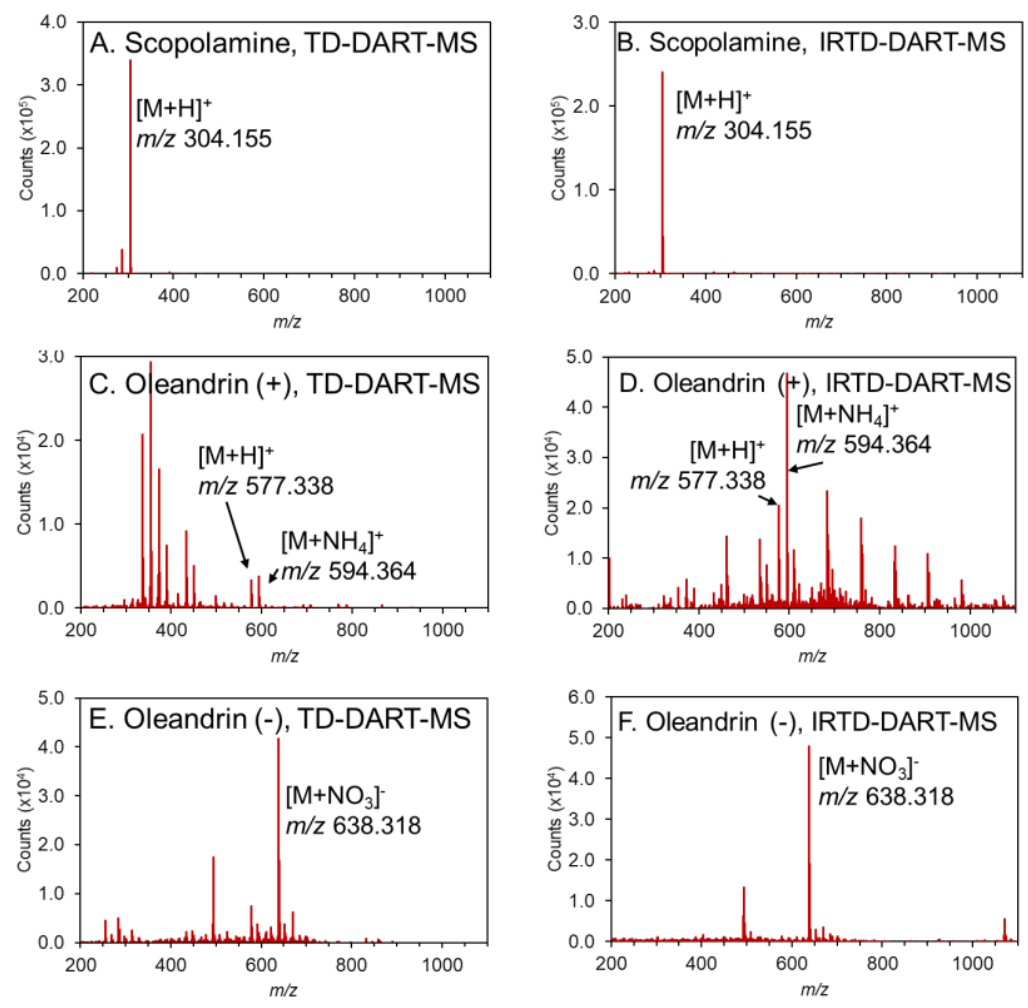

Figure 2. Representative TD-DART-MS mass spectra of scopolamine (A.), oleandrin in positive ionization mode (C.) and oleandrin in negative ionization mode (E.). Also pictured are representative IRTD-DARTMS mass spectra of scopolamine (B.), oleandrin in positive ionization mode (D.), and oleandrin in negative ionization mode (F.).

Negative ionization mode with TD-DART-MS also enabled detection of the remaining three compounds digoxin, digitoxin, and lanatoside. While detection of deprotonated molecule peaks or adducted molecules was not possible, diagnostic fragment ions were observed for all three compounds, as shown in Figure 
3(A.) (digitoxin), Figure S6 (digoxin), and S7 (lanatoside). Fragmentation, potentially due to thermal decomposition, occurred at each of the ether linkages between the rings. Many of the fragment ions produced were also nitrate adducts, instead of radical or deprotonated molecules. Sensitivities for these compounds were in the tens to hundreds of nanograms and were based upon the $\mathrm{m} / \mathrm{z} 452$ base peak in each spectrum.
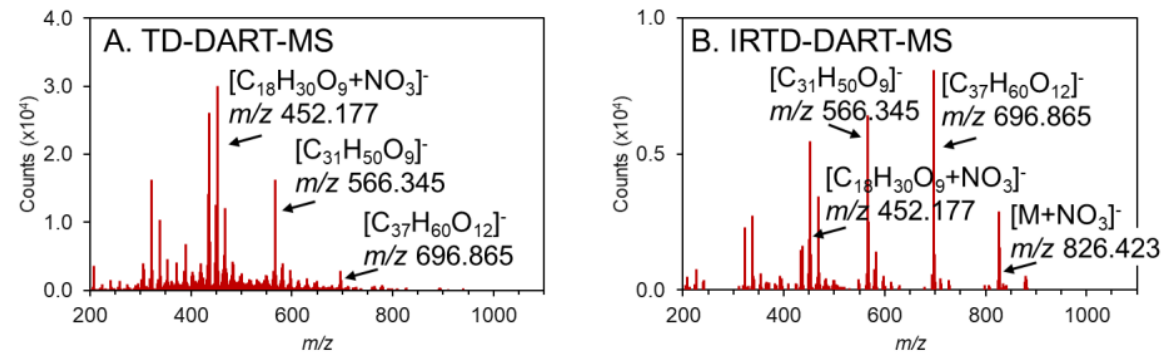

Figure 3. Representative TD-DART-MS (A.) and IRTD-DART-MS (B.) mass spectrum of digitoxin in negative ionization mode.

The ability to detect digoxin, digitoxin, and lanatoside with higher temperature thermal desorption led to the investigation of IRTD-DART-MS. Unlike TD-DART-MS, which uses a heating block to maintain an isothermal temperature, IRTD-DART-MS employs a broad spectrum near-IR lamp which when activated on demand, provides a ramped thermal desorption profile with maximum temperature based on emission duration. An example of a temperature profile for these experiments $\left(400{ }^{\circ} \mathrm{C}\right.$ with $100 \%$ power, $10 \mathrm{~s}$ duration) is shown in Figure S8. The ramped thermal desorption profile allows for the ability to desorb both thermally labile and thermally stable compounds in a single analysis without major thermal decomposition effects.

Evaluation of the seven toxins using IRTD-DART-MS, yielded similar results to TD-DART-MS. For hypaconitine, hyoscyamine, oleandrin, and scopolamine, sensitive detection in positive ionization mode was achieved with the formation of the $[\mathrm{M}+\mathrm{H}]^{+}$or $\left[\mathrm{M}-\mathrm{C}_{2} \mathrm{H}_{3} \mathrm{O}_{2}\right]^{+}$ions. Oleandrin was also observable in negative ionization mode as a nitrate adduct with a factor of five greater sensitivity than TD-DART-MS. For digoxin and digitoxin, detection of the intact molecule with a nitrate adduct was possible in negative ionization mode, Figure 3(B.) and Figure S6, which was not achieved using TD-DART-MS. Detection of intact lanatoside was not possible, but larger $\mathrm{m} / \mathrm{z}$ fragment ions, up to nominal $\mathrm{m} / \mathrm{z} 712$ (Figure S7) were observed. For these compounds, a high degree of fragmentation or decomposition was still observed. Detection levels for digoxin and lanatoside, measured using the base peak of each spectra were an order of magnitude, or more, better than TD-DART-MS (Table 1).

Table 2. Approximate detection limits for all DART-MS variations. The average signal to noise ratio for each measurement is reported in the parentheses, with uncertainties representing the standard deviations 
of triplicate measurements. N.D. indicates that the compound was not detected even at the highest mass tested $(1 \mu \mathrm{g})$. Note that oleandrin is listed in both ionization modes.

\begin{tabular}{|c|c|c|c|}
\hline Compound & DART-MS & TD-DART-MS & IRTD-DART-MS \\
\hline & \multicolumn{3}{|c|}{ Positive lonization Mode } \\
\hline Hypaconitine & $5 \mathrm{ng}(45 \pm 29)$ & $0.5 \mathrm{ng}(53 \pm 26)$ & $2 \mathrm{ng}(160 \pm 7)$ \\
\hline Hyoscyamine & $0.1 \mathrm{ng}(23 \pm 17)$ & $0.1 \mathrm{ng}(18 \pm 12)$ & $0.1 \mathrm{ng}(14 \pm 10)$ \\
\hline Oleandrin & $100 \mathrm{ng}(19 \pm 4)$ & $10 \mathrm{ng}(6 \pm 2)$ & $50 \mathrm{ng}(39 \pm 18)$ \\
\hline Scopolamine & $1 \mathrm{ng}(19 \pm 5)$ & $0.1 \mathrm{ng}(37 \pm 15)$ & $0.1 \mathrm{ng}(16 \pm 10)$ \\
\hline & \multicolumn{3}{|c|}{ Negative lonization Mode } \\
\hline Digitoxin & N.D. & $10 \mathrm{ng}(9 \pm 5)$ & $10 \mathrm{ng}(38 \pm 20)$ \\
\hline Digoxin & N.D. & $100 \mathrm{ng}(11 \pm 9)$ & $10 \mathrm{ng}(37 \pm 8)$ \\
\hline Lanatoside & N.D. & $200 \mathrm{ng}(10 \pm 7)$ & $5 \mathrm{ng}(11 \pm 6)$ \\
\hline Oleandrin & $100 \mathrm{ng}(80 \pm 37)$ & $2 \mathrm{ng}(5 \pm 1)$ & $10 \mathrm{ng}(16 \pm 8)$ \\
\hline
\end{tabular}

\section{Detection of Toxins in Seed Mash}

While establishing the ability to readily and sensitively detect seed-based toxins is valuable, the ability to detect the toxins in the complex matrices of seed mashes or seed mash extracts is equally as important. To determine if this would be feasible, seed mashes were created from six different seed species $(A$. napellus, $D$. inoxia, $D$. stramonium, $N$. oleander, $T$. peruviana, and $D$. purpurea) and analyzed by all three DART-MS variants in both positive and negative ionization modes. Due to a limited supply of seeds, only two seeds from each species were used to create the seed mash and seed mash extract for each technique. Determination of the presence of toxins was completed using the SearchFromList function of the Mass Mountaineer (Diablo Analytical, Antioch, CA, USA) software package with $1 \%$ relative intensity and \pm 5 mmu mass accuracy thresholds.

A summary of toxin detection in the six seed species is presented in Table 3. Toxins in the Datura genus seeds were the most readily detectable. They exhibited strong responses for scopolamine and hyoscyamine present in both the extract and seed mash across nearly all techniques, an example of which is shown in Figure 4. Significant differences in the relative concentrations of scopolamine and hyoscyamine were observed across all techniques, with a stronger response for scopolamine in $D$. inoxia compared to a higher hyoscyamine response for $D$. stramonium. D. inoxia seeds have been reported to contain 0.205 $\mu \mathrm{g} / \mathrm{mg}$ scopolamine[31]. Previous work has developed quantitative methods to determine the amount of scopolamine and hyoscyamine in seeds at different stages in plant growth from the $D$. stramonium species and found concentrations of $0.012 \mu \mathrm{g} / \mathrm{mg}$ to $0.089 \mu \mathrm{g} / \mathrm{mg}$ and $0.170 \mu \mathrm{g} / \mathrm{mg}$ to $0.387 \mu \mathrm{g} / \mathrm{mg}$, respectively[3]. Another study found the concentration of scopolamine $(0.36 \mu \mathrm{g} / \mathrm{mg}$ to $0.69 \mu \mathrm{g} / \mathrm{mg})$ and hyoscyamine (1.69 $\mu \mathrm{g} / \mathrm{mg}$ to $2.71 \mu \mathrm{g} / \mathrm{mg}$ ) varied by growing location[32]. 
Outside of the Datura genus, detection of toxins became more difficult. No technique was able to detect digoxin or digitoxin from the $D$. purpurea seeds. For the remaining seed species, only two of the variations were able to detect the toxins, and the techniques that were capable of detection were not consistent throughout. The main reason for the inability to detect these compounds is likely due to concentrations below the limit of detection of the technique. It is not surprising the detection of oleandrin from $N$. oleander seeds proved difficult since one study estimated the oleander concentration to be $0.143 \%$ to $0.160 \%$ by weight[33]. Given that the mash from only two seeds was analyzed for each of these studies, and only a fraction of that mash was used for a single analysis, an insufficient amount of toxin was likely present to elicit a response. If it were possible to analyze seed mash from a larger number of seeds, the probability of detection may be greater, especially for the methanol extract. Interestingly, IRTD-DART-MS failed to detect toxins in seeds outside of the Datura genus even though it had, generally, the lowest approximate detection limits. Direct IR absorption by the seed matrix may have potentially led to preferential thermal desorption processes and detrimental matrix effects. Competitive ionization also likely played a role in the detection of these compounds, as evidenced by the large number of additional peaks present in both the seed mash and seed mash extract spectra.
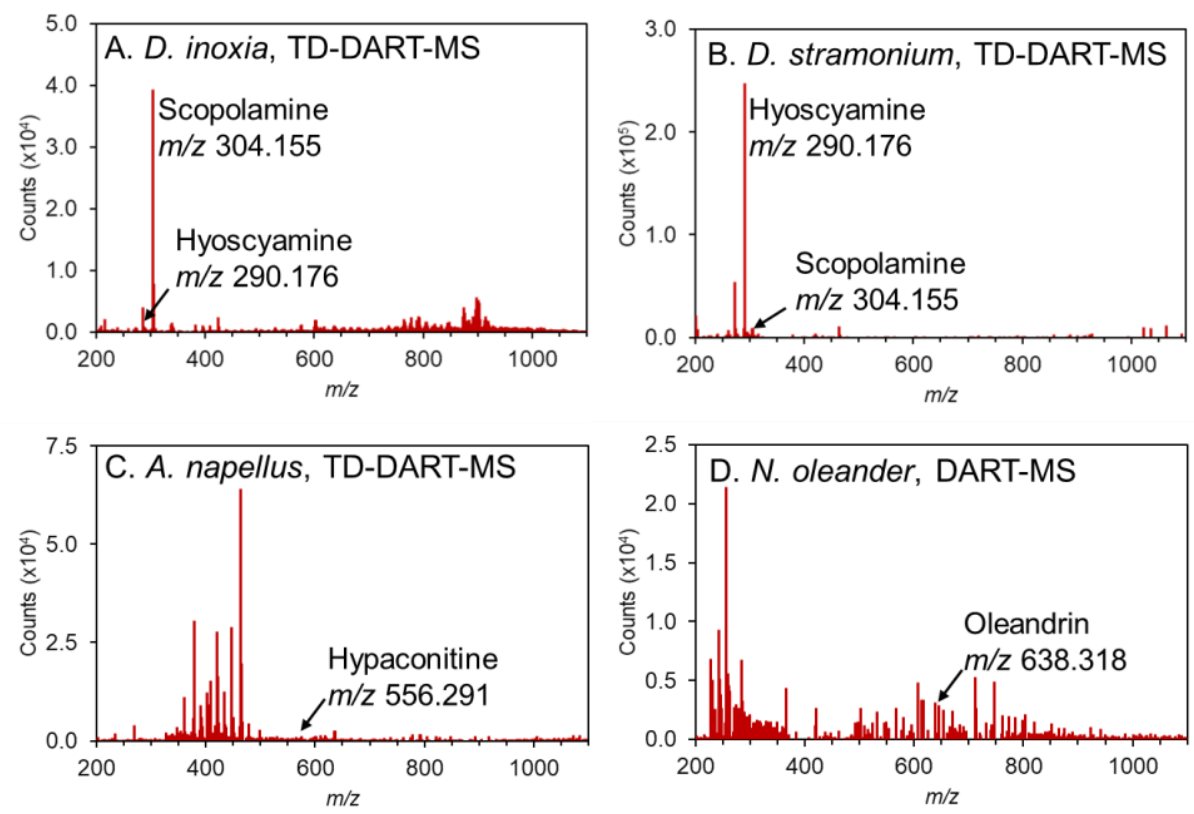

Figure 4. Representative TD-DART-MS positive mode mass spectra of the seed mash from $D$. inoxia (A.), $D$. stramonium (B.), and A. napellus (C.) seeds. Also shown is the DART-MS mass spectrum from the $N$. oleander seed mash (D.). 
Table 3. Summary data for the detection of toxins in the seed mashes and seed mash extracts. "D" indicates that the toxin was detectable in the dry seed mash while " $E$ " indicates that the toxin was detectable in the seed mash extract. An empty cell indicates detection was not achieved. Detection of toxins was attempted in both positive and negative ionization modes.

\begin{tabular}{|c|c|c|c|c|}
\hline Seed Species & DART & TD-DART & IRTD-DART & Toxin \\
\hline Aconitum napellus & & $\mathrm{E}$ & & Hypaconitine \\
\hline \multirow{2}{*}{ Datura inoxia } & $\mathrm{D}, \mathrm{E}$ & $\mathrm{D}, \mathrm{E}$ & $\mathrm{D}, \mathrm{E}$ & Scopolamine \\
\cline { 2 - 5 } & $\mathrm{D}, \mathrm{E}$ & $\mathrm{D}, \mathrm{E}$ & $\mathrm{D}, \mathrm{E}$ & Hyoscyamine \\
\hline \multirow{2}{*}{ Datura stramonium } & $\mathrm{D}, \mathrm{E}$ & $\mathrm{D}, \mathrm{E}$ & $\mathrm{D}, \mathrm{E}$ & Scopolamine \\
\cline { 2 - 5 } & $\mathrm{D}, \mathrm{E}$ & $\mathrm{D}, \mathrm{E}$ & $\mathrm{D}, \mathrm{E}$ & Hyoscyamine \\
\hline Nerium oleander & $\mathrm{D}$ & $\mathrm{E}$ & & Oleandrin \\
\hline Thevetia peruviana & $\mathrm{D}$ & & & Oleandrin \\
\hline Digitalis purpurea & & & & Digoxin \\
\hline
\end{tabular}

\section{Differentiation of Seed Species Based on Mass Spectral Signatures}

Given the difficulties in detecting all toxins from the seed mashes and extracts (i.e., targeted differentiation), PCA was employed to investigate seed differentiation based on the positive ionization mode full mass spectral signatures produced using TD-DART-MS. Figure 5 displays the scores plot of the first three principal components as determined using the procedure defined in the Materials and Methods section. PCA enabled differentiation of the seed species based on both the toxins present and the underlying seed matrices. A. napellus, $D$. inoxia, and $D$. stramonium samples were readily differentiable. The sample preparation method demonstrated little effect on the principal components. D. purpurea, T. peruviana, and $N$. oleander were also differentiable, but not to the same degree, with single replicates falling outside the main clusters (Figure 5). The first principal component (PC1) separated the seeds from the Datura genus (D. inoxia and $D$. stramonium) from the rest of the seed species. The strong mass spectral response to the scopolamine and hyoscyamine toxins in the Datura genus drove this separation (loading plots in Figure S9). The second principal component (PC2) separated $A$. napellus from the rest of the seed species by the strong ion distribution displayed in Figure $4 \mathrm{C}$ in the range of $\mathrm{m} / \mathrm{z} 350 \mathrm{to} \mathrm{m} / \mathrm{z} 500$. The third principal component (PC3) differentiated the two Datura seeds based on the relative magnitude of scopolamine and hyoscyamine. As alluded to in the previous section, $D$. inoxia exhibited stronger scopolamine signal, while $D$. stramonium exhibited stronger hyoscyamine signal. Though $D$. purpurea, T. peruviana, and $N$. oleander were differentiable by signals observed in PC1 and PC2 (Figure 5), further principal components aided in 
that differentiation. However, only the first three were reported here for ease of visualization. This analysis demonstrated the utility of multivariate statistics in the differentiation and potential classification of seeds based on their mass spectral response (i.e., more than just the toxin). The sample set of seeds used here was rather small, however, a clear path for using PCA to classify seeds was introduced.

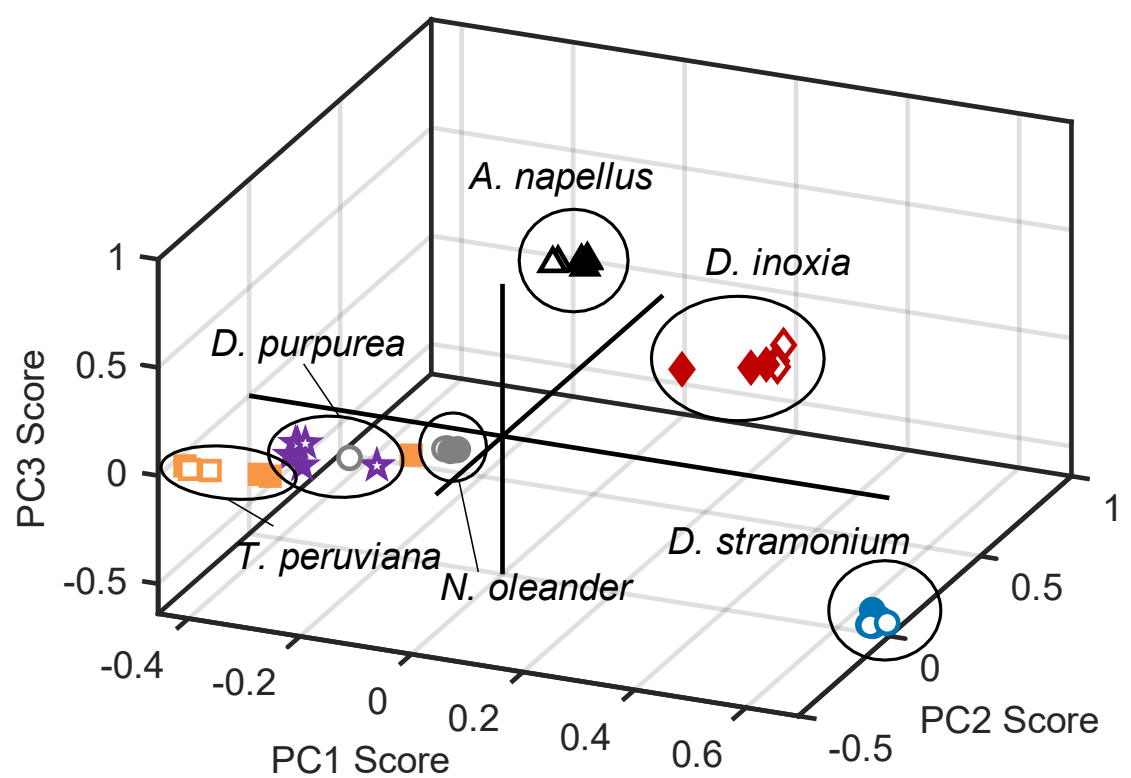

Figure 5. PCA scores plot of dry seed mash (filled data points) and seed mash extract (open data points). Plot represents the first three principal components for easy visualization of seeds from $N$. oleander $(\bullet), D$. inoxia $(\star)$, D. purpurea $(\star), A$. napellus $(\boldsymbol{\Delta})$, D. stramonium $(\bullet)$, and $T$. peruviana $(₫)$.

\section{Conclusion}

Rapid detection of the seven toxins examined in this work was obtained using TD-DART-MS and IRTDDART-MS with approximate detection limits ranging in the single to hundreds of nanograms. Toxins with larger molecular weights (digoxin, digitoxin, and lanatoside) were not detected by traditional DART-MS because of the inability to achieve sufficient thermal desorption. Some toxins only elicited responses, or stronger responses, in negative ionization mode. Detection of the toxin in seed was inconsistent and difficult for seeds outside of the Datura genus, which produced strong and readily identifying responses for scopolamine and hyoscyamine. Detection of the toxin in other seed species was likely hindered by a combination of small sample size and competitive ionization. This work demonstrated the ability to use ambient ionization mass spectrometry techniques like DART-MS for the rapid, presumptive identification of seed-based toxins from seed mashes and seed mash extracts. 


\section{Disclaimer}

Certain commercial products are identified in order to adequately specify the procedure; this does not imply endorsement or recommendation by NIST, nor does it imply that such products are necessarily the best available for the purpose. Names of commercial manufacturers are provided for information only and inclusion does not imply endorsement by the FBI or the U.S. Government. The views expressed are those of the authors and do not necessarily reflect the official policy or position of the FBI or the U.S. Government. This research was supported in part by an appointment to the Visiting Scientist Program at the FBI Laboratory Division, administered by the Oak Ridge Institute of Science and Education, through an interagency agreement between the US Department of Energy and the FBI. This is publication no. 21-18 of the Laboratory Division of the Federal bureau of Investigation.

\section{References}

[1] M. Wink, Mind-Altering and Poisonous Plants of the World, Timber Press, Portland, OR, 2008.

[2] S. Kohls, B.M. Scholz-Böttcher, J. Teske, P. Zark, J. Rullkötter, Cardiac glycosides from Yellow Oleander (Thevetia peruviana) seeds, Phytochemistry. 75 (2012) 114-127. https://doi.org/10.1016/j.phytochem.2011.11.019.

[3] E. Miraldi, A. Masti, S. Ferri, I. Barni Comparini, Distribution of hyoscyamine and scopolamine in Datura stramonium, Fitoterapia. 72 (2001) 644-648. https://doi.org/10.1016/S0367-326X(01)00291-X.

[4] L. Feldberg, O. Schuster, E. Elhanany, O. Laskar, S. Yitzhaki, S. Gura, Rapid and sensitive identification of ricin in environmental samples based on lactamyl agarose beads using LC-MS/MS (MRM), J. Mass Spectrom. 55 (2020) e4482. https://doi.org/10.1002/jms.4482.

[5] S.M. Darby, M.L. Miller, R.O. Allen, Forensic determination of ricin and the alkaloid marker ricinine from castor bean extracts, J. Forensic Sci. 46 (2001) 15097J. https://doi.org/10.1520/JFS15097J.

[6] I.A. Wasfi, O. Zorob, N.A. Al katheeri, A.M. Al Awadhi, A fatal case of oleandrin poisoning, Forensic Sci. Int. 179 (2008) e31-e36. https://doi.org/10.1016/j.forsciint.2008.05.002.

[7] Y. Gaillard, G. Pepin, Poisoning by plant material: review of human cases and analytical determination of main toxins by high-performance liquid chromatography-(tandem) mass spectrometry, J. Chromatogr. B. 733 (1999) 181-229. https://doi.org/10.1016/S0378-4347(99)00181-4.

[8] J.H. Gross, Direct analysis in real time--a critical review on DART-MS, Anal. Bioanal. Chem. 406 (2014) 63-80. https://doi.org/10.1007/s00216-013-7316-0.

[9] E. Sisco, T.P. Forbes, Forensic applications of DART-MS: a review of recent literature, Forensic Chem. 22 (2021) 100294. https://doi.org/10.1016/j.forc.2020.100294.

[10] C.N. McEwen, Atmospheric-Pressure Solid Analysis Probe (ASAP), in: Encyclopedia of Analytical Chemistry, John Wiley \& Sons, New York, NY, 2010. https://doi.org/10.1002/9780470027318.a9045.

[11] R.R. Steiner, Use of DART-TOF-MS for screening drugs of abuse, in: Analysis of Drugs of Abuse, Humana Press, New York, NY, 2018: pp. 59-68. https://doi.org/10.1007/978-1-4939-8579-1_5.

[12] E. Sisco, J. Dake, C. Bridge, Screening for trace explosives by AccuTOF-DART: an in-depth validation study, Forensic Sci. Int. 232 (2013) 160-168. https://doi.org/10.1016/j.forsciint.2013.07.006.

[13] M. Marić, J. Marano, R.B. Cody, C. Bridge, DART-MS: A new analytical technique for forensic paint analysis, Anal. Chem. 90 (2018) 6877-6884. https://doi.org/10.1021/acs.analchem.8b01067.

[14] M. Maric, C. Bridge, Characterizing and classifying water-based lubricants using direct analysis in real time time of flight mass spectrometry, Forensic Sci. Int. 266 (2016) 73-79. https://doi.org/10.1016/j.forsciint.2016.04.036.

[15] S. Singh, S.K. Verma, Study of the distribution profile of piperidine alkaloids in various parts of Prosopis juliflora by the application of direct analysis in real time mass spectrometry (DART-MS), Nat. Prod. Bioprospect. 2 (2012) 206-209. https://doi.org/10.1007/s13659-012-0069-1. 
[16] F. Zhou, H. Zhu, S. Liu, K. Ma, F. Song, Z. Liu, In situ analysis for herbal pieces of Aconitum plants by using direct analysis in real time mass spectrometry, Chinese J. Chem. 33 (2015) 241-246. https://doi.org/10.1002/cjoc.201400692.

[17] A.D. Lesiak, R.B. Cody, A.J. Dane, R.A. Musah, Plant seed species identification from chemical fingerprints: a high-throughput application of direct analysis in real time mass spectrometry, Anal. Chem. 87 (2015) 87488757. https://doi.org/10.1021/acs.analchem.5b01611.

[18] A.D. Lesiak, R.B. Cody, A.J. Dane, R.A. Musah, Rapid detection by direct analysis in real time mass spectrometry (DART-MS) of psychoactive plant drugs of abuse: The case of Mitragyna speciosa aka “Kratom," Forensic Sci. Int. 242 (2014) 210-218. https://doi.org/10.1016/j.forsciint.2014.07.005.

[19] A.D. Lesiak, R.B. Cody, M. Ubukata, R.A. Musah, Direct analysis in real time high resolution mass spectrometry as a tool for rapid characterization of mind-altering plant materials and revelation of supplement adulteration - The case of Kanna, Forensic Sci. Int. 260 (2016) 66-73.

https://doi.org/10.1016/j.forsciint.2015.12.037.

[20] S. Singh, Enhancing phytochemical levels, enzymatic and antioxidant activity of spinach leaves by chitosan treatment and an insight into the metabolic pathway using DART-MS technique, Food Chem. 199 (2016) 176-184. https://doi.org/10.1016/j.foodchem.2015.11.127.

[21] H.J. Kim, E.H. Jee, K.S. Ahn, H.S. Choi, Y.P. Jang, Identification of marker compounds in herbal drugs on TLC with DART-MS, Arch. Pharm. Res. 33 (2010) 1355-1359. https://doi.org/10.1007/s12272-010-0909-7.

[22] E. Sisco, T.P. Forbes, M.E. Staymates, G. Gillen, Rapid analysis of trace drugs and metabolites using a thermal desorption DART-MS configuration, Anal. Methods. 8 (2016) 6494-6499. https://doi.org/10.1039/C6AY01851C.

[23] E. Sisco, M.E. Staymates, T.P. Forbes, Optimization of confined direct analysis in real time mass spectrometry (DART-MS), Analyst. 145 (2020) 2743-2750. https://doi.org/10.1039/DOAN00031K.

[24] T.P. Forbes, E. Sisco, M. Staymates, Detection of non-volatile inorganic oxidizer-based explosives from wipe collections by infrared thermal desorption - direct analysis in real time mass spectrometry, Anal Chem. 90 (2018) 6419-6425. https://doi.org/10.1021/acs.analchem.8b01037.

[25] M.S. Wagner, D.G. Castner, Characterization of adsorbed protein films by time-of-flight secondary ion mass spectrometry with principal component analysis, Langmuir. 17 (2001) 4649-4660. https://doi.org/10.1021/la001209t.

[26] J.J. Perez, P.M. Flanigan, J.J. Brady, R.J. Levis, Classification of smokeless powders using laser electrospray mass spectrometry and offline multivariate statistical analysis, Anal. Chem. 85 (2013) 296-302. https://doi.org/10.1021/ac302661k.

[27] T.P. Forbes, J.R. Verkouteren, Forensic Analysis and differentiation of black powder and black powder substitute chemical signatures by infrared thermal desorption-DART-MS, Anal. Chem. 91 (2019) 1089-1097. https://doi.org/10.1021/acs.analchem.8b04624.

[28] E.L. Robinson, E. Sisco, Detection of brodifacoum and other rodenticides in drug mixtures using thermal desorption direct analysis in real time mass spectrometry (TD-DART-MS), J. Forensic Sci. 64 (2019) 10261033. https://doi.org/10.1111/1556-4029.13978.

[29] L. P. Harding, G.M. B. Parkes, J. D. Townend, Parameters affecting ion intensities in transmission-mode direct analysis in real-time mass spectrometry, Analyst. 139 (2014) 4176-4180. https://doi.org/10.1039/C4AN00859F.

[30] G.A. Harris, C.E. Falcone, F.M. Fernández, Sensitivity "hot spots" in the direct analysis in real time mass spectrometry of nerve agent simulants, J. Am. Soc. Mass Spectrom. 23 (2012) 153-161. https://doi.org/10.1007/s13361-011-0276-8.

[31] James A. Duke, Handbook of Phytochemical Constituents of GRAS Herbs and Other Economic Plants: Herbal Reference Library, 2nd ed., CRC Press, Boca Raton, FL, 2000.

[32] M. Friedman, C.E. Levin, Composition of jimson weed (Datura stramonium) seeds, J. Agric. Food Chem. 37 (1989) 998-1005. https://doi.org/10.1021/jf00088a040.

[33] M.S. Karawya, S.I. Balbaa, S.E. Khayyal, Estimation of cardenolides in Nerium oleander, Planta Med. 23 (1973) 70-73. https://doi.org/10.1055/s-0028-1099414. 


\title{
Supplementary Information for:
}

\section{Rapid, Presumptive Identification of Seed-Based Toxins using Direct Analysis in Real Time Mass Spectrometry (DART-MS) and its Variants}

\author{
Edward Sisco ${ }^{*}$, Natalie Damaso ${ }^{b}$, Elizabeth L. Robinsona, James M. Robertson ${ }^{c}$, and Thomas P. Forbes ${ }^{a}$ \\ aNational Institute of Standards and Technology, 100 Bureau Drive, Gaithersburg, MD 20899

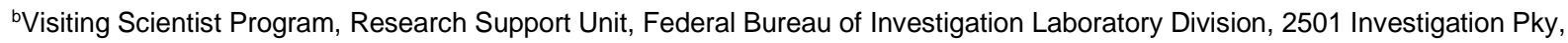 \\ Quantico, VA, 22135, USA
}

${ }^{\mathrm{c}}$ Research Support Unit, Federal Bureau of Investigation Laboratory Division, 2501 Investigation Pky, Quantico, VA, 22135, USA

*edward.sisco@nist.gov, 301-975-2093
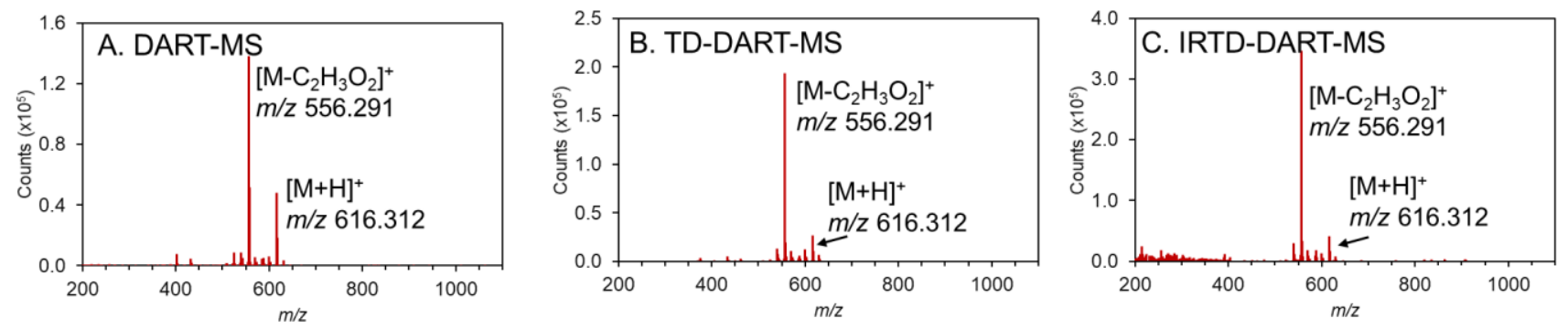

Figure S1. Representative mass spectra of hypaconitine when analyzed by (A.) DART-MS, (B.) TDDART-MS, and (C.) IRTD-DART-MS.
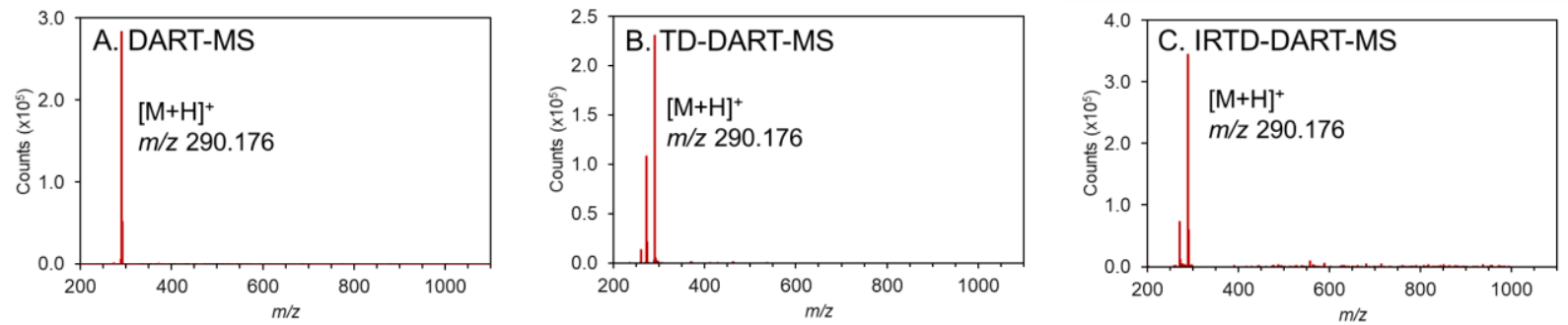

Figure S2. Representative mass spectra of hyoscyamine when analyzed by (A.) DART-MS, (B.) TDDART-MS, and (C.) IRTD-DART-MS. 

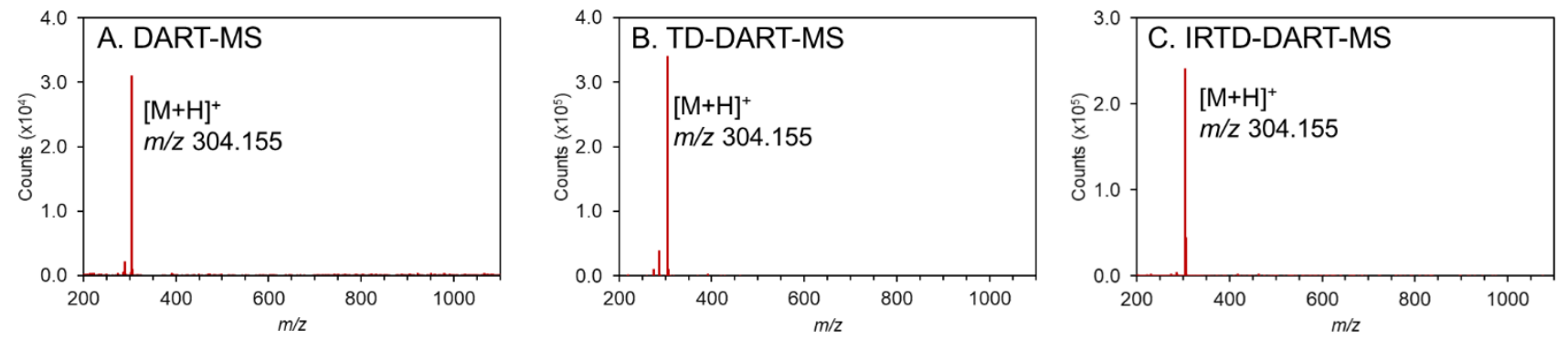

Figure S3. Representative mass spectra of scopolamine when analyzed by (A.) DART-MS, (B.) TDDART-MS, and (C.) IRTD-DART-MS.
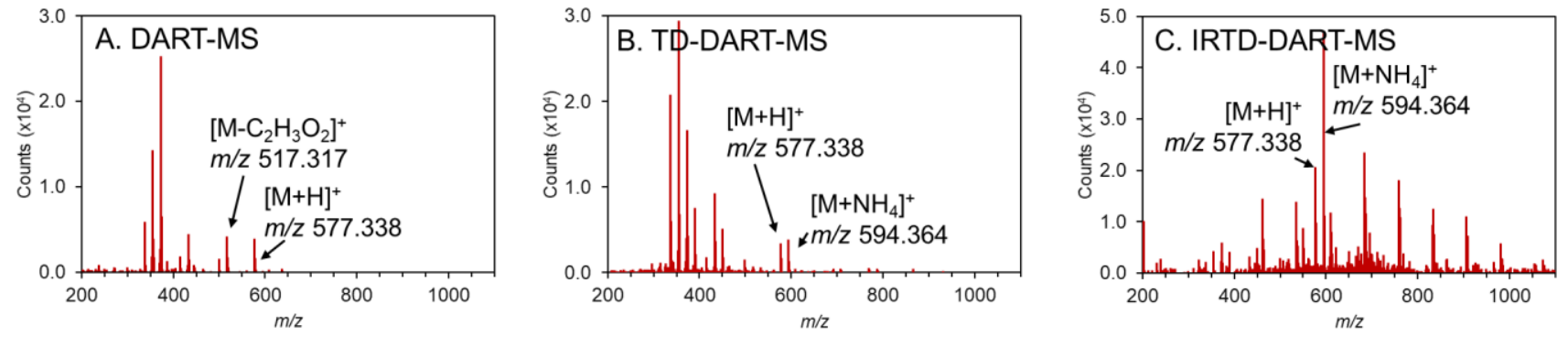

Figure S4. Representative positive ionization mode mass spectra of oleandrin when analyzed by (A.) DART-MS, (B.) TD-DART-MS, and (C.) IRTD-DART-MS.
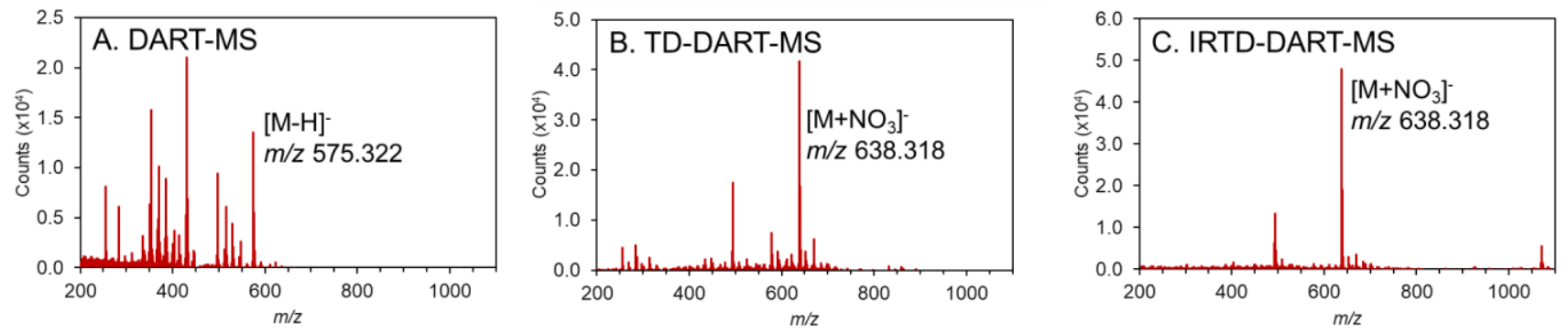

Figure S5. Representative negative ionization mode mass spectra of oleandrin when analyzed by (A.) DART-MS, (B.) TD-DART-MS, and (C.) IRTD-DART-MS. 

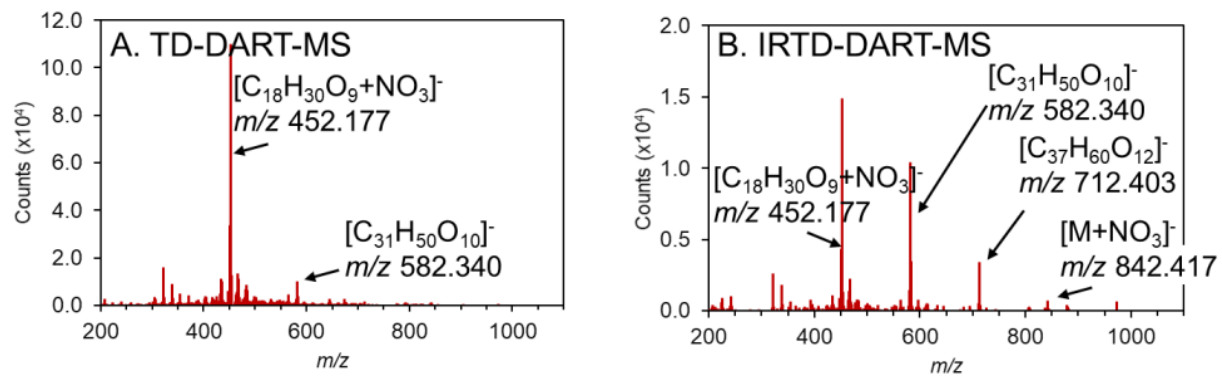

Figure S6. Representative mass spectra of digoxin when analyzed by TD-DART-MS (A.) and IRTDDART-MS (B.) in negative ionization mode.
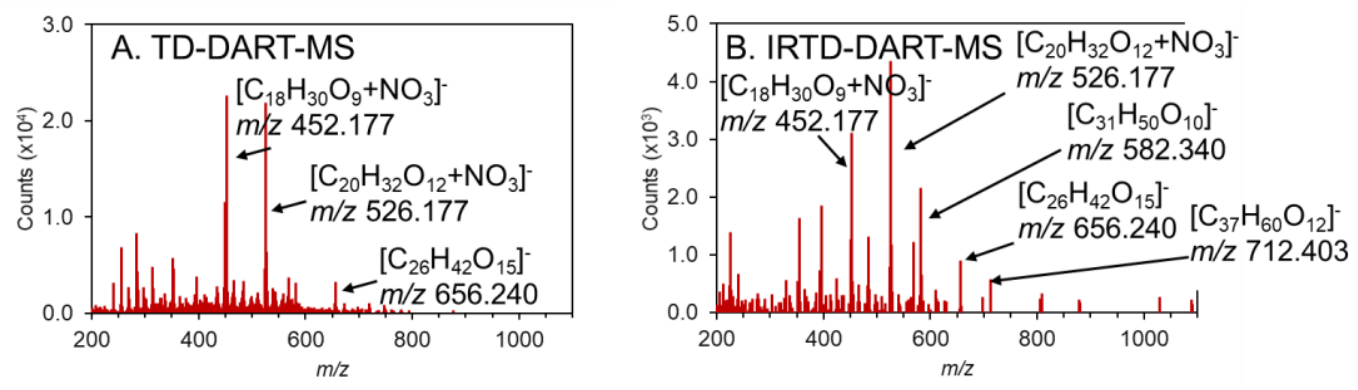

Figure S7. Representative mass spectra of lanatoside when analyzed by TD-DART-MS (A.) and IRTDDART-MS (B.) in negative ionization mode.
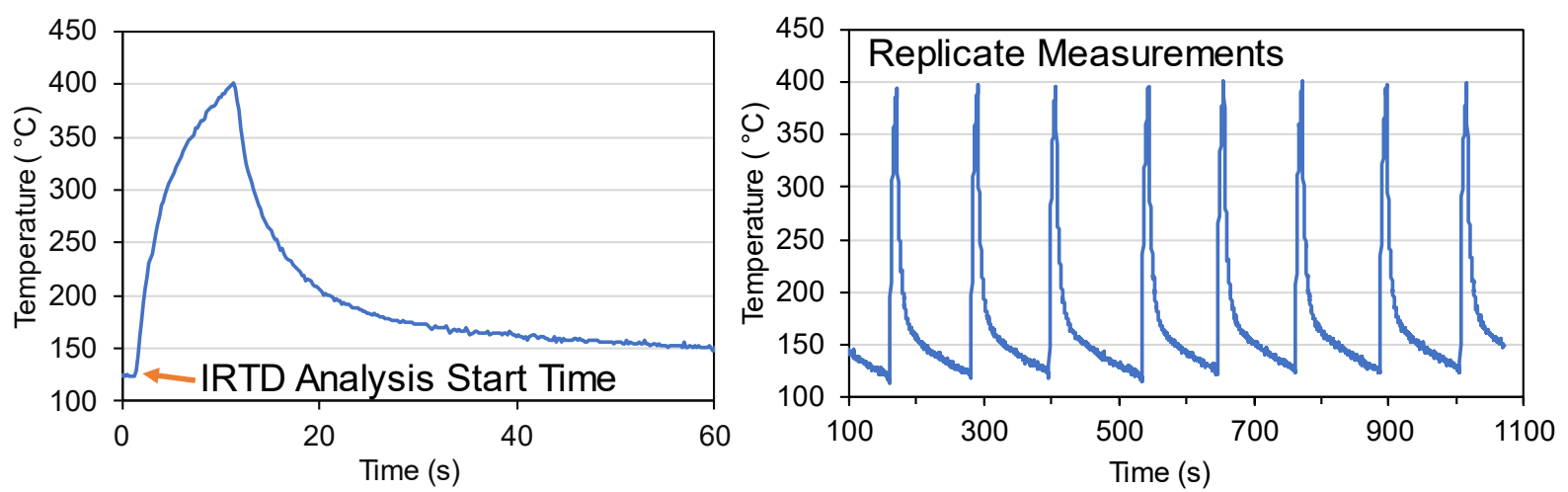

Figure S8. Representative temperature profiles for IRTD-DART-MS experiments. 

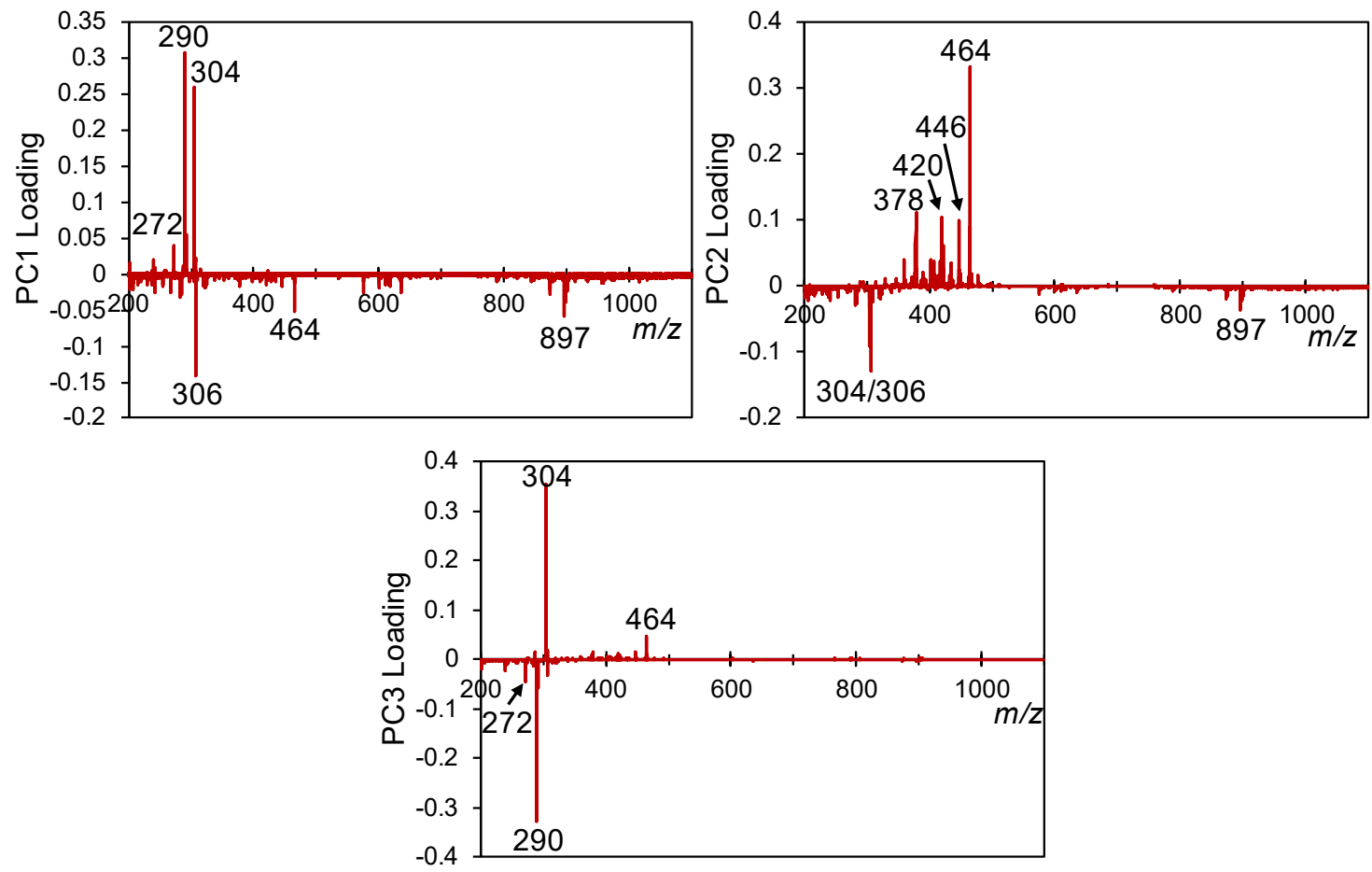

Figure S9. PCA loading plots of seed mass spectrometry chemical signatures for the first three principal components. 